\title{
Suicidal Behavior among Adolescents: Correlates, Confounds, and (the Search for) Causal Mechanisms
}

\section{Citation}

Nock, Matthew. 2009. Suicidal behavior among adolescents: correlates, confounds, and (the search forl causal mechanisms. Journal of the American Academy of Child and Adolescent Psychiatry 48: 237-239.

\section{Published Version}

doi:10.1097/CHI.0b013e318196b944

\section{Permanent link}

http://nrs.harvard.edu/urn-3:HUL.InstRepos:4134407

\section{Terms of Use}

This article was downloaded from Harvard University's DASH repository, and is made available under the terms and conditions applicable to Open Access Policy Articles, as set forth at http:// nrs.harvard.edu/urn-3:HUL.InstRepos:dash.current.terms-of-use\#OAP

\section{Share Your Story}

The Harvard community has made this article openly available.

Please share how this access benefits you. Submit a story.

\section{Accessibility}


Words: 1337

Suicidal Behavior among Adolescents:

Correlates, Confounds, and (the search for) Causal Mechanisms

Matthew K. Nock, Ph.D.

Dr. Nock is with the Department of Psychology, Harvard University.

Correspondence to Matthew K. Nock, Ph.D., Harvard University, 33 Kirkland Street, Cambridge, MA 02138, e-mail: nock@wjh.harvard.edu. 
The death of a child is a terrible tragedy. When the death occurs at the child's own hands it is particularly devastating. Unfortunately, such deaths are not uncommon, as suicide is a leading cause of death worldwide and the third leading cause of death among children and adolescents in the US. ${ }^{1}$ Preventing suicide requires that we develop a better understanding of why people kill themselves.

Explanatory models in clinical science typically develop by first identifying correlates of the outcome of interest; then conducting well-controlled, prospective, experimental studies to identify causal relations among variables; followed by more fine-grained studies aimed at delineating causal mechanisms (i.e., the pathways or processes through which the correlate influences the outcome). ${ }^{2,3}$ The development and testing of explanatory models is significantly more challenging in the case of suicidal behavior given the clinical, ethical/legal, and methodological challenges that characterize work in this area. For instance, although suicide is a leading cause of death, suicidal behaviors have a relatively low base-rate in the community and so studies of suicidal behaviors typically require very large sample sizes to test the complex models that will be needed to understand and predict suicidal behavior. In addition, concerns about failing to adequately monitor or treat suicidal behavior, or about increasing suicidal behavior in response to experimental manipulation, often preclude the use of experimental designs. Furthermore, the stigma associated with suicidal behaviors can lead to underreporting or to avoidance of research studies altogether. As a result of these challenges, studies of suicidal behavior have provided valuable information about the correlates of these outcomes, but many questions remain about the nature of these correlations (e.g., what are the mediators and moderators?) and about the causal mechanisms that explain the processes through which these relations exist. For instance, dozens of research studies have shown that suicidal behavior occurs 
at higher rates among those who: are female, are adolescents, have a history of violence (or victimization), have a family history of mental disorders, and have a mental or alcohol/substance use disorder. ${ }^{1}$ However, little is known about how or why each of these factors is correlated with suicidal behavior. Why do girls make more suicide attempts than boys? Why are there such enormous racial/ethnic differences in suicide rates? How or why (i.e., through what processes) are mental disorders like depression and alcohol abuse/dependence associated with suicidal behavior?

Three articles in this issue of the Journal overcome many of the limitations of prior work in this area and in doing so move us slightly further along the path from knowledge of correlation to understanding of causal mechanisms. ${ }^{5-7}$ Notably, each study uses a large $(N>1,000)$ and representative sample of adolescents, and each goes beyond simple tests of bivariate correlations to provide more fine-grained information about the nature of the relations between previously identified correlates and suicidal behaviors. In doing so, they bring us one step closer to understanding the causal mechanisms involved in the development of suicidal behavior.

The prevalence of suicidal behaviors varies significantly across countries, cultures, and racial/ethnic groups around the world. ${ }^{110}$ In the US, although $90.5 \%$ of suicides occur among European Americans, ${ }^{11}$ the suicide rate for Black adolescent males has risen significantly over the past several decades and now approximates that of European Americans. ${ }^{11}$ The article by Joe and colleagues, ${ }^{7}$ which examines the prevalence and correlates of suicide ideation and attempts among a nationally representative sample $(N=1,170)$ of Black adolescents in the US, is especially important given this context. The authors document that $7.5 \%$ of Black adolescents report seriously thinking about killing themselves at some point in their lifetime, and $2.7 \%$ report a past 
suicide attempt, underscoring the broad scope of this problem. The fact that female sex, older adolescent age, and the presence and accumulation of mental disorders again emerge as correlates of suicide ideation and attempts — a finding consistent with studies conducted across many different countries ${ }^{10}$ - suggests that there is strong consistency in the correlates of suicidal behaviors across diverse groups. Interestingly, only $52.7 \%$ Black adolescent suicide attempters report ever having met criteria for a mental disorder—a rate much lower than observed in prior studies of adolescents more generally. ${ }^{12}$ Thus, in addition to raising questions about what causal mechanisms can explain why mental disorders are associated with suicidal behavior, this study highlights the importance of moving beyond the study of mental disorders to better understand how a broader range of factors might help to explain the development of this behavior.

For instance, prior studies have revealed that bullying is correlated with suicidal behavior. However, it is not known whether bullying somehow causes suicidal behavior in the perpetrator (or victim), or if this correlation is simply the result of confounding by some third, explanatory variable. Klomek and colleagues ${ }^{5}$ shed light on this issue using data from a large $(N=5,302)$ population-based birth cohort in Finland assessed at 8-years of age for the presence of bullying and victimization (i.e., being the victim of bullying) and followed until age 25 -years. The authors show that bullying and victimization during childhood are indeed associated with increased odds of a subsequent suicide attempt. Importantly, their study advances understanding of this relation by showing how these effects differ for boys and girls and after adjusting for conduct disorder and major depression (i.e., potential confounds). Among boys, bullying (but not victimization) is associated with increased odds of suicide attempts when examined alone; however, this association is no longer significant after adjusting for conduct disorder and depression. This suggests that bullying is not causally related to suicidal behavior but instead 
that they are correlated because both are consequences of conduct disorder-a known risk factor for suicidal behavior (especially among boys). ${ }^{8,9}$ Results are the opposite for girlsvictimization (but not bullying) is associated with suicide attempts, even after adjusting for conduct disorder and depression. This study provides much finer detail about the nature of the associations between bullying and suicidal behavior and sets the stage for future studies that address key remaining questions. Most importantly, why is conduct disorder associated with suicidal behavior? Perhaps it is not conduct disorder per se that is important, but the presence of impulsive-aggressive tendencies, which itself increases the likelihood of conduct disorder and suicidal behavior (e.g., by increasing the likelihood of acting on suicidal thoughts). For girls, how, why, and for whom does being victimized lead to suicidal behavior?

Studies also have shown that alcohol use disorders are associated with an increased risk of suicidal behavior and suicide death among adolescents. ${ }^{8,9}$ It is not clear, however, if this association varies across developmental periods. Aseltine and colleagues ${ }^{6}$ examine the relation between heavy episodic drinking (HED) and the presence of a recent suicide attempt among adolescents participating in a large, cross-sectional, school-based suicide screening program $(N=32,217)$. The authors find that HED is associated with suicide attempts, even after controlling for depression (i.e., a potential confound). They also take the important next step of decomposing their overall finding - in this case testing whether the relation between HED and suicide attempts differs by age. They report that the association is strongest in those $\leq 13$ yearsold and decreases monotonically with increasing age. One possible interpretation of this finding is that the influence of HED on suicidal behavior (if there is one) decreases over time. A more parsimonious explanation is that HED it is not causally related to suicidal behavior, but instead early HED is a marker for some other factor (e.g., poor behavioral inhibition, poor decision- 
making, cognitive precociousness) that is causally related to suicide attempts. Clarifying the nature of these relations is not merely an academic exercise. Prevention and intervention programs targeting correlates that are not causally related to suicidal behavior are unlikely to be effective. For instance, if bullying, HED, and suicidal behaviors are correlated because they are all consequences of an impulse-aggressive personality style, clinical attention should not focus on the former, but the latter. Once revealed, information about causal mechanisms will not only enhance scientific understanding of suicidal behaviors, ${ }^{4}$ but will guide the development of more effective methods of preventing these tragic outcomes.

Disclosure: The author reports no conflict of interest. 


\section{References}

1. Nock MK, Borges G, Bromet EJ, Cha CB, Kessler RC, Lee S. Suicide and suicidal behavior. Epidemiologic Reviews. 2008;30(1):133-154.

2. Kazdin AE, Nock MK. Delineating mechanisms of change in child and adolescent therapy: methodological issues and research recommendations. Journal of Child Psychology and Psychiatry. Nov 2003;44(8):1116-1129.

3. Hill AB. The environment and disease: Association or causation? Proceedings of the Royal Society of Medicine. 1965;58:295-300.

4. Kendler KS. Explanatory models for psychiatric illness. American Journal of Psychiatry. Jun 2008;165(6):695-702.

5. Klomek AB. Childhood bullying behaviors as a risk for suicide attempts and completed suicides: A population-based birth cohort study. Journal of the American Academy of Child and Adolescent Psychiatry. this issue.

6. Aseltine RH, Schilling EA, James A, Glanovsky JL, Jacobs D. Age variability in the association between heavy episodic drinking and adolescent suicide attempts: Findings from a large-scale school-based screening. Journal of the American Academy of Child and Adolescent Psychiatry. this issue.

7. Joe S, Baser RS, Neighbors HW, Caldwell CH, Jackson JS. 12-month and lifetime prevalence of suicide attempts among Black adolescents in the National Survey of American Life. Journal of the American Academy of Child and Adolescent Psychiatry. this issue. 
8. Brent DA, Baugher M, Bridge J, Chen T, Chiappetta L. Age- and sex-related risk factors for adolescent suicide. Journal of the American Academy of Child and Adolescent Psychiatry. Dec 1999;38(12):1497-1505.

9. Shaffer D, Gould MS, Fisher P, et al. Psychiatric diagnosis in child and adolescent suicide. Archives of General Psychiatry. Apr 1996;53(4):339-348.

10. Nock MK, Borges G, Bromet EJ, et al. Cross-national prevalence and risk factors for suicidal ideation, plans, and attempts in the WHO World Mental Health Surveys. British Journal of Psychiatry. 2008;192(2):98-105.

11. CDC. Web-based Injury Statistics Query and Reporting System (WISQARS) Fatal Injuries: Mortality Reports. National Center for Injury Prevention and Control, Centers for Disease Control and Prevention (producer) [http://www.cdc.gov/nipc/wisqars]. Available at: http://www.cdc.gov/nipc/wisqars. Accessed November 5, 2008.

12. Bridge JA, Goldstein TR, Brent DA. Adolescent suicide and suicidal behavior. Journal of Child Psychology and Psychiatry. Mar-Apr 2006;47(3-4):372-394. 